\title{
Okul Yöneticisinin Kullandığı Motivasyonel Dilin Öğretmen Tükenmişliğindeki Rolü
}

\author{
The Role of Motivational Language Used by School \\ Adminisrator in Teacher Burnout
}

\begin{abstract}
Selçuk DEMIR*
Öz: Bu çalışmanın amacı okul yöneticisinin motivasyonel dili ile öğretmen tükenmişliği arasındaki ilişkinin belirlenmesidir. Araştırmada ilişsisel tarama modeli kullanılmıştır. Araştırmanın örneklemini, Hatay il merkezinde bulunan kamu ortaokullarında 2017-2018 eğitim-öğretim yılında görev yapmakta olan öğretmenler arasından yansız olarak seçilmiş 33 okulda çalışan 348 öğretmen oluşturmaktadır. Verilerin toplanmasında "Motivasyonel Dil Ölçeği" ve "Öğretmen Tükenmişlik Ölçeği" kullanılmıştır. Veriler SPSS programı ile analiz edilmiştir. Araştırma bulgularına göre; okul yöneticisinin kullandığı motivasyonel dil öğretmen tükenmişliğini negatif ve anlamlı olarak yordamaktadır. Ayrıca, motivasyonel dilin yönlendirici dil alt boyutu öğretmen tükenmişliğini anlamlı olarak yordarken, empatik dil ve anlam oluşturucu dil alt boyutları öğretmen tükenmişliğini anlamlı olarak yordamamaktadır. Bu çalışma; liderler, etkili sonuçlara ulaşmak için motivasyonel dilin her üç unsurunu da uygun bir şekilde birlikte kullanmalılar, şeklindeki Motivasyonel Dil Teorisi'nin ana varsayımlarından birinin öğretmen tükenmişliğindeki azalış bağlamında geçerli olmadığını göstermiştir. Öğretmen tükenmişliğini azaltmak isteyen okul yöneticisinin öğretmenler tarafından algılanan motivasyonel dilini ve özellikle yönlendirici alt boyutunu geliştirmeleri önemli görülmektedir.
\end{abstract}

Anahtar Kelimeler: Motivasyonel dil, tükenmişlik, okul yöneticisi, öğretmen

\begin{abstract}
The purpose of this study is to determine the relationship between school administrator's motivational language and teacher burnout. In this research relational screening model was used. The research sample consists of 348 teachers in 33 schools that were selected randomly from the middle schools affiliated to the Ministry of National Education at Hatay's city center in 2017-2018 academic year. Data analyses were performed with the program of SPSS. Data were collected by "Motivational Language Scale" and "Teacher Burnout Scale". According to the study findings, motivational language used by school administrator negatively and significantly predicts teacher burnout. While directing-giving sub-dimension of motivational language significantly predicts teacher burnout, empathetic and meaningmaking sub-dimensions do not predict. This study has revealed one of the main assumptions of Motivational Language Theory that leaders have to use all three sub-facets of motivational language together properly to get effective outputs has not been confirmed by the context of a decrease in teacher burnout. It is crucial for school administrator to invest in developing and strengthening motivational language and especially its directing-giving component in order to reduce teacher burnout.

Keywords: Motivational language, burnout, school administrator, teacher
\end{abstract}

\section{Giriş}

Lider stratejik iletişiminin, çalışanların psikolojik yapıları üzerinde etkisinin olduğu bilinmesine rağmen, özellikle eğitim örgütlerindeki sözel iletişim taktiklerine ilişkin çalışmaların sınırlı sayıda oluşu ve kavramsal çerçevenin darlığı dikkat çekmektedir. Öğretmenlerin gizil güçlerini ortaya çıkaran ve kurumdaki verimlilik artı̧̧ını sağlayan motivasyonel dil kavramı yöneticilere stratejik sözel iletişime dair uygulanabilir ve kolay taktikler sunmaktadır. Bu kapsamda motivasyonel dilin rol belirsizliği ve rol çatışmasının oluşmasını önlemek suretiyle bireylerin olumsuz tutumlarından olan tükenmişlikleri üzerindeki etkisi önem kazanmaktadır. Tükenmişlik, örgütlerde bireysel ve örgütsel olumsuz çıktıların yaşanmasına neden olabilecek

* Dr., MEB/ Kırıkhan İmam Hatip Ortaokulu, Hatay-Türkiye, ORCID: 0000-0003-2904-6443, e-posta: selcuk_demirs@hotmail.com 
olumsuz psikolojik bir süreçtir. Bu süreci öğretmenlerin yaşamaması ya da bu süreçle başarılı bir şekilde mücadele etmelerinde yöneticilerinin rolü büyüktür. Bu bağlamda olumlu tutumları arttırdığı ve olumsuz tutumları ise azalttığı bilinen motivasyonel dil kullanımı, yöneticiler açısından zaruriyet göstermektedir. Bu çalışma Motivasyonel Dil Teorisi'ne ilişkin mevcut kavramsal çerçeveyi sunmakla kalmayıp genişletmekte, daha anlaşılır kılmakta ve yöneticilerin yönetim konusundaki yeterliklerini desteklemektedir.

\section{Motivasyonel dil}

Liderin gücünü yönetebilmesinin iletişim diline hâkim olmasiyla mümkün olduğu bilinmektedir. Yapılan araştırmalarda (Banks, 2014; Brannon, 2011; Conger, 1991; Demir, 2018a, 2018b; Karaaslan, 2010; Mayfield ve Mayfield, 2002, 2004, 2006, 2009a, 2009b, 2010; Mayfield, Mayfield ve Kopf, 1995, 1998; Simmons ve Sharbrough III, 2013; Sullivan, 1988) liderin kullandığı iletişim dilinin, astlarıyla etkileşiminde önemli bir faktör olduğu tespit edilmiştir. Bu nedenle daha yüksek kalitede lider iletişiminin nasıl elde edileceği konusu önem kazanmıştır (Mayfield ve diğerleri, 1995; Murray, 2015; Sullivan, 1988). Sullivan (1988) motivasyonel dil teorisinde, lider iletişiminde kaliteyi daha da arttırmak amacıyla anlaşılması ve uygulanması kolay iletişim taktiklerine yönelik bir model sunmaktadır. İleri sürdüğü model dört varsayımdan oluşmaktadır. Birinci olarak motivasyonel dil sözel iletişimin anlamlı ve küçük birimleri olan üç dil ediminden oluşur. Bu dil edimleri yönlendirici dil, empatik dil ve anlam oluşturucu dil edimi şeklindedir (Demir, 2018a, 2018b, 2018c; Mayfield ve diğerleri, 1995, 1998; Sullivan, 1988). Yönlendirici dil; liderin belirsizliği azaltma yoluyla çalışanlara görevler, hak ve sorumluluklar, ödüller ve amaçlar konusunda bilgilendirmeler yaptığında kullanılmış olmaktadır. Empatik dil; çalışanların başarılarının olumlu yönlerinin vurgulanması, iş ve kişisel sorunlarına özel ilgi gösterilmesi, anlayışlı ve kibar davranması ve memnuniyetlerini sağlama durumlarında oluşur (Brannon, 2011; Mayfield ve Mayfield, 2002; Mayfield ve diğerleri, 1995, 1998; Sullivan, 1988). Anlam oluşturucu dil; liderler örgüt kültürünü, yapısını, faaliyetlerini ve değerlerini çalışanlara aktardığında ortaya çıkar (Conger, 1991). Motivasyonel dil teorisinin ikinci varsayımı, liderlerin davranışlarının söylemleri ile tutarlılık göstermesidir (Demir, 2018c). Üçüncüsü ise, liderin bu üç dil edimini kullanmasının, en iyi kalitede iletişim kurmasını sağlayacağını varsaymasıdır (Gutierrez-Wirsching, Mayfield, Mayfield ve Wang, 2015; Mayfield ve diğerleri, 1995; Sullivan, 1988). Dördüncü varsayımı ise, iletişimin yönetici ile çalışan arasında çift yönlü olmasıdır (Demir, 2018a, 2018b).

Rol belirsizliği ve rol çatışması gibi öğretmenlerin işleriyle ilgili belirsizliklerinin olması tükenmişlik yaşamalarına neden olmaktadır (Schwap ve Iwanichi, 1982). Rol çatışması, bireyden iki ya da daha fazla birbiriyle tutarsız rol davranışlarının aynı anda yapılmasının istenmesi sonucu olmaktadır. Rol belirsizliği ise görevler, hak ve bunların getirdiği yükümlülüklerin neler olduğuna ve nasıl gerçekleştirileceğine ilişkin bilgilerin net olarak ortaya konulmaması sonucu oluşmaktadır (Çokluk, 2014). Motivasyonel dilin kullanılması ile örgütlerde bu gibi istenmeyen durumların oluşması önlemektedir. Nitekim motivasyonel dil kullanımı ile örgüt lideri çalışanlarının görevlerini, görev sınırlılıklarını açık olarak tanımlamakta ve onların belirsizliklerini gidermektedir.

\section{Tükenmişlik}

Uzun bir süre strese maruz kalma ve bu stresle mücadelede başarısız olma öğretmenlerin öğretmen tükenmişliği adı verilen bir durumu yaşamalarına neden olabilmektedir. Altıntaş (2014); başa çıkılamayan stresin insanın dengesini bozacağını, sonrasında tükenme ve bitkinlik nöbetlerinin ortaya çıkacağını belirtmektedir. Kyriacou (2000) öğretmen tükenmişliğinin üç şekilde oluşacağını vurgulamaktadır: (1) davranış olarak tükenme, (2) fiziksel tükenme ve (3) heyecanın tükenmesi.

Davranış olarak tükenme: Öğretmenlerin çalışma isteklerini kaybetmeleri ve işlerinden memnuniyet düzeylerinin azalması şeklinde görülebilir. Öğretmenler öğrencileriyle daha az ilgilenir ve onlarla daha az zaman geçirir. Onlara karşı soğuk ve katıdırlar. Mesleğiyle ilgili daha fazla bir şey yapmaya isteksiz hale gelir. 
Fiziksel tükenme: Öğretmenlerin kendilerini bedenen yorgun hissetmeleridir. Gün bitiminde enerjileri de tamamen bitmiştir. Sıklıkla okul çıkışı çok yorgun olduklarını belirtirler.

Heyecanın tükenmesi: Öğretmenler gün boyunca pozitif tutumlarını sürdüremezler. İse karşı bir isteksizlik ve geri çekilme durumu hâkimdir. Öğretmenlik mesleğine olan bağl1lı̆̆ azalmıştır. Dolayısıyla işlerini daha iyi yaptıklarını düşünmezler.

Psikolojik bir süreç olarak kabul edilen tükenmişlik, meslekten ve çalışmadan kopuşa yol açmaktadır (Dolgun, 2015). Tükenmişlik; sağlık, eğitim ve güvenlik gibi yoğun iletişim gerektiren meslek gruplarında hizmet veren kişilerde daha belirgin biçimde görülmektedir (Çokluk, 2014). Öğretmenler, yoğun tükenmişlik yaşadıkları belirlenen gruplardan biridir. Bir okulda öğretmen tükenmişliği sadece bu psikolojik durumu yaşayan öğretmeni değil, öğrencileri ve kendini mesleğine adamış idealist öğretmen arkadaşlarını da olumsuz yönde etkileyebilir (Hock, 1988). Tükenmişlik yaşayan öğretmen, öğrencilerine daha az ilgi gösterir ve sempatik davranır, sınıftaki durumlara daha az hoşgörüyle yaklaşır, derslere daha sık hazırlıksız girer, fiziksel ve duygusal olarak yorgun hisseder. Ayrıca öğretmenin işine ilişkin bağlılı̆̆ ve memnuniyeti azalır, işe devamsızlığı artar (Byrne, 1991; Russell, Altmaier ve Van Zelzen, 1987).

\section{Okul yöneticisinin motivasyonel dili ile öğretmen tükenmişliği arasındaki ilişki}

Liderin stratejik iletişiminin, örgütlerde istenen çalışan çıktıları üzerinde olumlu etkileri bulunduğu (Brannon, 2011; Demir, 2018a, 2018b, 2018c; Gutierrez-Wirsching ve diğerleri, 2015; Mayfield ve Mayfield, 2002; Mayfield ve diğerleri, 1995, 1998; Sullivan, 1988) ve olumsuz çalışan tutumları üzerinde ise negatif etkileri olduğu (Mayfield ve Mayfield, 2007) önceki çalışmalardan bilinmektedir. Altıntaş (2014); bireylerin iyi performans sergileyebilmelerinde örgütün kendilerinden hangi beklentilerinin olduğunu bilmeleri gerektiğini, bu beklentilerin neler olduğunu bilmediklerinde gerilim yaşayacaklarını ileri sürmektedir. Bu yaşanan gerilimin uzun süreli olması ve baş edilememesi ise tükenmişliğe yol açmaktadır. Simmons ve Sharbrough III (2013); çalışanların belirli bir davranışın belirli bir amaçla gerçekleşeceğini bilmelerinin, buna inanmalarının ve sonuca yükledikleri anlamların değerli hale gelmesinin liderin iletişim becerileriyle gerçekleştiğini ortaya çıkarmışlardır. Schwap ve Iwanichi (1982); rol çatışması ve rol belirsizliğinin olduğu okullarda, öğretmenlerin ögrencilerine yönelik tavırlarının olumsuz olduğunu, ayrıca bu öğretmenlerin duygusal tükenme ve yorgunluk yaşadıklarını tespit etmiştir. Çalışmalarında rol çatışmasının ve rol belirsizliğinin tükenmişliğin bir yordayıcısı olduğunu bulmuşlardır. Ayrıca çalışmalarındaki diğer bir önemli bulgu ise özellikle rol belirsizliğinin kişisel başarıyı azalttığıdır. Yöneticilerin örgüt bireylerinden neler beklendiğini açıklaması, bireylerin görev tanımlarını belirgin hale getirmesi ve belirsizlik yaşamalarının önüne geçmeleri, kullanacakları stratejik iletişim metodu aracıllğıyla mümkün olmaktadır (Demir, 2018a, 2018b, 2018c; Mayfield ve diğerleri, 1995, 1998; Sullivan, 1988).

Demir (2018a); okul yöneticilerinin stratejik sözel iletişim taktiklerini kullanmasının, öz yeterlik inançlarını arttıracağını bulmuştur. Öz yeterlik gibi psikolojik güçleri artan öğretmenler, uzun süreli stresin yoğun etkileriyle mücadele edebilir. Böylelikle öğretmenlerin, fiziksel ya da psikolojik olarak tükenmelerinin azalması sağlanabilir. Nitekim önceki çalışmalarda (Aliyev ve Tunç, 2015; Bolat, 2011; Gam, Kim ve Jeon, 2016; Rahmati, 2015; Rogala ve diğerleri, 2016; Sarıçam ve Sakız, 2014) bireylerin psikolojik açıdan daha güçlü olmalarını sağlayan öz yeterlik algılarının, tükenmişlik düzeyleri ile negatif yönde ilişkili olduğu tespit edilmiştir.

Stratejik iletişimin kolay uygulanabilir bir metotu olan motivasyonel dilin kullanımı ile bireylerin işlerinden dolayı bir gerilim yaşamalarının önüne geçilebilmektedir. Nitekim motivasyonel dil, çalışanların olumlu tutumları arttırıp olumsuz tutumlarını azaltmaktadır (Demir, 2018c). Önceki çalışmalarda (Bradley, 2014; Kreitner ve Kinichi, 2009; Schermerhorn ve diğerleri, 2011), stres ve gerilim duygularının uzun süre ve yoğun biçimde yaşanmamasının ise tükenmişliği azalttı̆̆ 1 bilinmektedir. 


\section{Araştırmanın amacı}

Bu çalışmada algılanan yönetici motivasyonel dili ile öğretmen tükenmişliği arasındaki ilişkinin incelenmesinin yanı sıra öğretmen tükenmişlik düzeyinin motivasyonel dilin alt unsurları ile ilişkisi de açığa çıkarılmaya çalışılmıştır. Böylelikle motivasyonel dilin tükenmişlikle bağına dair daha kapsamlı bilgiler sunulması hedeflenmiştir. Bu araştırma diğer örgütlerde olduğu gibi eğitim örgütlerinde de önemli performans çıtıları sunan motivasyonel dil ve tükenmişlik kavramlarına yoğunlaşılması açısından, diğer çalışmalara da referans niteliği taşımaktadır. $\mathrm{Bu}$ bağlamda, okul yöneticilerinin stratejik sözel iletişimlerinde motivasyonel dilin unsurlarından yerinde ve uygun bir şekilde yararlanmaları önemli görülmektedir. $\mathrm{Bu}$ araştırmada önceki çalışma bulgularına dayanılarak, okul yöneticisi motivasyonel dilinin olumsuz çıtılara yol açan öğretmen tükenmişliği ile arasında bir köprü bulunduğu ileri sürülmektedir. Araştırmanın amacı, okul yöneticisinin algılanan motivasyonel dili ile öğretmen tükenmişliği arasındaki ilişkiyi belirlemektir. Bu temel amaç bağlamında aşağıdaki hipotezler geliştirilmiştir:

H1: Okul yöneticisinin motivasyonel dili, öğretmen tükenmişliğini negatif anlamlı olarak yordamaktadir.

H2: Okul yöneticisinin yönlendirici dili, öğretmen tükenmişliğini negatif anlamlı olarak yordamaktadir.

H3: Okul yöneticisinin empatik dili, öğretmen tükenmişliğini negatif anlamlı olarak yordamaktadir.

H4: Okul yöneticisinin anlam oluşturucu dili, öğretmen tükenmişliğini negatif anlamlı olarak yordamaktadır.

\section{Yöntem}

\section{Araștırma modeli}

$\mathrm{Bu}$ araştırmada iki ya da daha fazla değişken arasındaki birlikte değişim varlığını ve/ veya düzeyini tespit etmeyi amaçlayan ilişkisel tarama modeli kullanılmıştır (Büyüköztürk, Çakmak, Akgün, Karadeniz ve Demirel, 2012; Karasar, 2012). İlişkisel tarama modeli, değişkenler arasında neden-sonuç olasılığına ilişkin fikir sunar ve bu modelde değişkenler yordayıcı olabilir (Büyüköztürk ve diğerleri, 2012; Fraenkel, Wallen ve Hyun, 2012; Sönmez ve Alacapınar, 2016). Motivasyonel dil ve alt boyutlarının öğretmen tükenmişliği ile ilişkisi ve tükenmişliğin motivasyonel dil tarafından yordanma gücü ölçekler aracılıyla tespit edilmeye çalışılmıştır.

\section{Örneklem}

Araştırmanın çalışma evreni 2017-2018 eğitim öğretim yılında Hatay il merkezindeki kamu ortaokullarında görev yapan öğretmenlerdir. Örnekleme alınan öğretmenlerin $(n=348)$ \%53.4'ünü kadınlar ( $\mathrm{n}=186)$ ve \%46.6'sını erkekler $(\mathrm{n}=162)$ oluşturmaktadır. Bu öğretmenlerin \%71.3'ü evli ( $n=248)$ iken \%28.7'si bekâr öğretmenlerden $(n=100)$ oluşmaktadır. Katılımcıların en fazla bulundukları yaş aralığını \%39.1 ile 31-40 yaş aralığındaki öğretmenler ( $\mathrm{n}=123)$, en az bulundukları yaş aralığını ise \%22.7 ile 41 yaş ve üstü öğretmenler (n=79) oluşturmaktadır. Ayrıca katılımcıların en fazla bulundukları kıdem aralığ $\% 54.3$ ile 1-10 yıl arası $(\mathrm{n}=189)$ ve en az bulundukları kıdem aralığı ise \%10.6 ile 21 yıl ve üzeri olduğu $(n=37)$ görülmektedir.

\section{Veri toplama}

Veri toplama yöntemleri

Araştırma değişkenlerinin ölçümünde motivasyonel dil ve tükenmişlik ölçekleri kullanılmıştır. Ölçekler beşli likert tipinde olup seçenekler, "1= Hiç katılmıyorum"; "2= Katılmıyorum"; " $3=$ Kismen kat1lyorum"; " $4=$ Kat1liyorum"; ve " $5=$ Tamamen kat1lyorum" şeklinde değişmektedir. Katılımcılardan kendi algılarına uygun olan yanıtı seçmeleri istenmiştir.

\section{Ölçme aracı}

Ölçeklere ilişkin bu çalışma kapsamında elde edilen bilgiler, aşağıda belirtilmektedir. 
Motivasyonel dil ölçeği: $\mathrm{Bu}$ araştırmada; okul yöneticisinin motivasyonel dilinin öğretmen algısına göre ölçümü için Mayfield ve diğerleri (1995) tarafindan geliştirilen ve Özen (2013) tarafından Türkçeye uyarlanan Motivasyonel Dil Ölçeği (MDÖ) (Motivational Language Scale) kullanılmıştır. Ölçeğin orijinal formu 24 maddeden ve üç boyuttan oluşmaktadır. Ölçeğin alt boyutları yönlendirici dil, empatik (cesaret verici) dil ve anlam oluşturucu (aitlik oluşturucu) dil şeklindedir. Motivasyonel dil ölçeğinin Bartlett Küresellik Testi sonucu anlamlı ve KaiserMeyer-Olkin (KMO) katsayısı .952 olduğundan veri setinin faktör analizi için uygun olduğu görülmüştür. Yönlendirici dil boyutun açıkladığ1 varyans yüzdesi 34.211, empatik dil (cesaret verici dil) boyutunun açıkladığ varyans yüzdesi 14.373, anlam oluşturucu dil (aitlik oluşturucu dil) boyutu tarafından açıklanan varyans yüzdesi 28.606 ve bu üç boyutun açıkladığı toplam varyans yüzdesi 77.189 olarak bulunmuştur. Cronbach's Alpha Güvenirlik Katsayısının yönlendirici dil boyutunda .950 , empatik dil boyutunda .865 , anlam oluşturucu dil boyutunda .939 ve ölçeğin tamamında .962 olduğu görülmüştür. Doğrulayıcı faktör analizi ile bu üç alt boyutlu yapının, kabul edilebilir düzeyde uyum değerleri ürettiği tespit edilmiştir (X2=216.819, $\mathrm{sd}=84, \mathrm{X} 2 / \mathrm{sd}=2.581, \mathrm{P}=0.000, \mathrm{RMSEA}=0.068, \mathrm{GFI}=0.924, \mathrm{IFI}=0.972, \mathrm{TLI}=.965, \mathrm{CFI}=0.972$ ).

Öğretmen tükenmişlik ölçeği: Bu ölçek; Pines (2005) tarafından geliştirilmiş olup, Tümkaya, Çam ve Çavuşoğlu (2009) tarafindan Türkçeye uyarlanmıştır. Ölçek 10 maddeden ve tek boyuttan oluşmaktadır. Bartlett Küresellik Testi sonucu anlamlı ve Kaiser-Meyer-Olkin (KMO) katsayıs1 .926 olduğundan veri matrisi faktör analizi için uygun olduğu görülmüştür. Faktör analizi sonucunda ölçekten atılan madde olmamıştır. Ölçek maddelerinin faktör yüklerinin .590 ile .884 arasında değiştiği görülmüştür. Tükenmişliğin açıkladığı varyans yüzdesi \%64.045 olarak bulunmuştur. Cronbach's Alpha Güvenirlik Katsayısının .934 olduğu görülmüştür. Doğrulayıcı faktör analizi ile bu tek boyutlu yapının, kabul edilebilir düzeyde uyum değerleri ürettiği tespit edilmiştir $(\mathrm{X} 2=13.675, \mathrm{sd}=5, \mathrm{X} 2 / \mathrm{sd}=2.735, \mathrm{P}=0.018, \mathrm{RMSEA}=0.071, \mathrm{GFI}=0.983$, $\mathrm{IFI}=0.995$, TLI=.987, CFI=0.993).

\section{İşlem}

$\mathrm{Bu}$ araştırmada tek tek bireylerin değil, seçkisiz olarak belirlenen grupların örneklem için seçilmesi olarak tanımlanan küme örnekleme yöntemi kullanılmıştır. Araştırmanın çalışma evreni olan Hatay il merkezinde her okul bir küme kabul edilip 33 ortaokul tesadüfî olarak seçilmiştir. Dağıtılan anketlerin 348 tanesinin geçerli olduğu tespit edilip değerlendirmeye alınmıştır. 348 öğretmenin \%95 güven düzeyi için yeterli olduğu görülmüştür (Field, 2009; Özdamar, 2003).

\section{Verilerin analizi}

Veriler toplandıktan sonra uç değerler temizlenmiş, çarpıklık ve basıklık katsayıları kontrol edilmiş, değişkenler arası ilişkilerin doğrusal olduğu ve normallik varsayımının sağlandığı açısından incelenmiştir. Veriler geçerlik ve güvenirlik açısından incelenmiştir. Bu araştırma kapsamında yapılan açımlayıcı faktör analizi ve doğrulayıcı faktör analizi sonuçları ve Cronbach's Alpha güvenirlik katsayıları kullanılan ölçeklerin geçerli ve güvenilir olduğunu göstermiştir. Bunun ardından değişkenler arasındaki ilişkiler korelasyon analizi ile tespit edilmiştir. Ardından basit ve çoklu doğrusal regresyon analizleri (stepwise yöntemiyle) kullanılarak incelenmiştir. Basit doğrusal regresyon analizinde bağımsız değişken motivasyonel dil; çoklu doğrusal regresyonda ise bağımsız değişkenler motivasyonel dilin yönlendirici dil, empatik dil ve anlam oluşturucu dil boyutları; her iki analizde de bağımlı değişken olarak öğretmen tükenmişliği alınmıştır.

Doğrulayıcı faktör analizi aşamasında, ölçeklerin faktör yapılarına bakılmış ve bazı kriterlere göre kabul edilebilir uyum değerleri üretip üretmedikleri incelenmiştir. Bu kriterler özetle; X2/sd oranının ikinin altında olması çok iyi bir uyumu, iki ile üç arasında olması ise kabul edilebilir bir uyumu göstermektedir. RMSEA değerinin 0.08 ile 0.05 arasında olmas 1 kabul edilebilir; 0.05 'in altında olması ise çok iyi bir uyum bulunduğunu belirtmektedir. GFI değerinin .085 ile .090 arasında olması kabul edilebilir; .90 ile .95 arasında olması iyi bir uyum 
bulunduğunu ortaya koymaktadır. IFI, CFI ve TLI değerlerinin 0.90 ile 0.95 arasında olmas kabul edilebilir; 0.95 'in üzerinde olması ise çok iyi bir uyum bulunduğunun göstergesidir (Arbuckle, 2009; Byrne, 2010; Kline, 2011).

\section{Bulgular}

\section{Değişkenlerle ilgili betimsel analizler ve korelasyon matrisi}

Öğretmenlerin, araştırma kapsamında uygulanan ölçme araçlarındaki maddelere katılım düzeylerini gösteren aritmetik ortalama, standart sapma değerleri ile değişkenler arası ilişkilerin düzeyi ve yönünün belirtildiği korelasyon değerleri birlikte Tablo 1'de verilmektedir.

Tablo 1.

Motivasyonel Dil ve Alt Boyutları ile Tükenmişlik Ortalama, Standart Hata, Standart Sapma Sonuçları ve Korelasyon Değerleri

\begin{tabular}{|c|c|c|c|c|c|c|c|c|}
\hline Değişkenler & $\overline{\bar{X}}$ & SS & $\begin{array}{l}\text { Std. } \\
\text { Hata }\end{array}$ & 1 & 2 & 3 & 4 & 5 \\
\hline 1. Mot. Dil & 3.73 & .86 & .04 & 1 & & & & \\
\hline 2. Yön. Dil & 3.90 & .88 & .04 & $.91 * *$ & 1 & & & \\
\hline 3. Emp. Dil & 3.54 & 1.03 & .05 & $.87 * * *$ & $.73 * * *$ & 1 & & \\
\hline 4. Anl. Dil & 3.53 & 1.03 & .05 & $.90 * * *$ & $.69 * * *$ & $.78 * * *$ & 1 & \\
\hline 5. Tükenmişlik & 2.10 & .86 & .04 & $-.23 * * *$ & $-.23 * * *$ & $-.22 * * *$ & $-.19 * * *$ & 1 \\
\hline
\end{tabular}

$* \mathrm{p}<, 05, * * \mathrm{p}<, 01, * * * \mathrm{p}<, 001$

Notlar: Mot. Dil: Motivasyonel dil genel, Yön. Dil: Yönlendirici Dil, Emp. Dil: Empatik Dil, Anl. Dil: Anlam Oluşturucu Dil

Tablo 1'e göre; okul yöneticisinin kullandığı motivasyonel dile ve motivasyonel dilin unsurlarına ilişkin öğretmen algıları kısmen yüksek düzeydedir. Tükenmişliğe ilişkin öğretmen algıları ise kısmen düşük düzeydedir. Okulda öğretmenler tarafından en yüksek düzeyde algılanan motivasyonel dil alt boyutunun yönlendirici dil, en düşük düzeyde algılanan motivasyonel dil alt boyutunun ise anlam oluşturucu dil olduğu görülmüştür. Diğer bir ifadeyle öğretmen algılarına göre yöneticiler, okulda en fazla yönlendirici dili ve en az ise anlam oluşturucu dili kullanmaktadırlar. Korelasyon matrisindeki ilişkilere bakıldığında, motivasyonel dil $(\mathrm{r}=-.23, \mathrm{p}<.01)$, yönlendirici dil alt boyutuna $(\mathrm{r}=-.23, \mathrm{p}<.01)$, empatik dil alt boyutuna $(\mathrm{r}=-$ $.22, \mathrm{p}<.01)$ ve anlam oluşturucu dil alt boyutuna $(\mathrm{r}=-.19, \mathrm{p}<.01)$ ilişkin algılar ile öğretmen tükenmişlik algıları arasındaki ilişkilerin negatif anlamlı olduğu tespit edilmiştir.

Okul yöneticisinin kullandığı motivasyonel dilin öğretmen tükenmişliğini yordaması Okul yöneticisinin kullandığı motivasyonel dilin, öğretmenin tükenmişliğini yordamasına ilişkin regresyon analizi sonuçları Tablo 2'de verilmiştir

Yapılan regresyon analizinde, demografik değişkenler 1.adımda kontrol edilerek 2. adımda okul yöneticisinin kullandığı motivasyonel dilin, öğretmen tükenmişliğini anlamlı bir şekilde yordadığı görülmektedir $\left(\beta=-.24^{* * *}, \quad \mathrm{p}<0.001\right)$. Öğretmenin, motivasyonel dilin kullanımına ilişkin algısındaki bir birimlik artış .24 birimlik öğretmen tükenmişliği azalışını sağlamaktadır. Okul yöneticisinin motivasyonel dili, öğretmen tükenmişliğindeki varyansın $\% 5.8$ 'ini açıklamaktadır $(\Delta \mathrm{R} 2=.058 ; \mathrm{p}<0.001)$. Okul yöneticisinin motivasyonel dil kullanımına ilişkin olumlu algılar arttıkça, öğretmen tükenmişliği azalmaktadır. 
Tablo 2

Okul Yöneticisinin Kullandığı Motivasyonel Dilin Öğretmen Tükenmişliğini Yordamasına İlişkin Regresyon Analizi Sonuçları

\begin{tabular}{|c|c|c|c|c|c|c|}
\hline Model & $\begin{array}{l}\text { Yordayıcı } \\
\text { değişkenler }\end{array}$ & $\mathrm{B}$ & Std. Hata & Beta & $\mathrm{t}$ & $\mathrm{p}$ \\
\hline \multirow{4}{*}{ 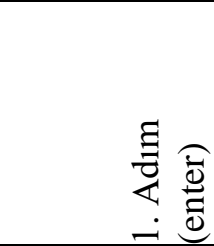 } & (sabit) & 1.80 & .43 & & 4.13 & .000 \\
\hline & $\begin{array}{l}\text { Cinsiyet } \\
\text { (dummy) }\end{array}$ & .11 & .09 & .06 & 1.12 & .263 \\
\hline & yas & .01 & .01 & .13 & .73 & .460 \\
\hline & k1dem & -.02 & .02 & -.17 & -1.02 & .308 \\
\hline \multirow{5}{*}{$\begin{array}{l}\Xi \\
\stackrel{\Xi}{Z} \\
\text { ¿ }\end{array}$} & (sabit) & 2.69 & .46 & & 5.78 & .000 \\
\hline & $\begin{array}{l}\text { cinsiyet } \\
\text { (dummy) }\end{array}$ & .10 & .09 & .06 & 1.12 & .260 \\
\hline & yas & .01 & .01 & .14 & .82 & .412 \\
\hline & k1dem & -.02 & .01 & -.20 & -1.19 & .233 \\
\hline & $\begin{array}{l}\text { motivasyonel } \\
\text { dil }\end{array}$ & -.24 & .05 & -.24 & -4.59 & .000 \\
\hline
\end{tabular}

Bağımlı değişken tükenmişlik

$\mathrm{R} 2$ değişim $=.058 \quad * \mathrm{p}<.05, * * \mathrm{p}<.01, * * * \mathrm{p}<.001$

Okul yöneticisinin kullandığı motivasyonel dilin alt boyutlarının öğretmen tükenmişliğini yordamasına ilişkin çoklu regresyon analizi sonuçları Tablo 3 'te verilmiştir.

Tablo 3.

Motivasyonel Dilin Yönlendirici Dil Alt Boyutunun Öğretmen Tükenmişliğini Yordamasına İlişkin Çoklu Regresyon Analizi Sonuçları

\begin{tabular}{|c|c|c|c|c|c|c|}
\hline Model & $\begin{array}{l}\text { Yordayıcı } \\
\text { değişkenler }\end{array}$ & B & Std. Hata & Beta & $\mathrm{t}$ & $\mathrm{p}$ \\
\hline \multirow{4}{*}{ 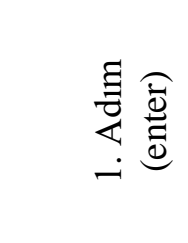 } & (sabit) & 1.80 & .43 & & 4.13 & .000 \\
\hline & $\begin{array}{l}\text { Cinsiyet } \\
\text { (dummy) }\end{array}$ & .11 & .09 & .06 & 1.12 & .263 \\
\hline & yas & .01 & .01 & .13 & .73 & .460 \\
\hline & k1dem & -.02 & .02 & -.17 & -1.02 & .308 \\
\hline \multirow{5}{*}{ 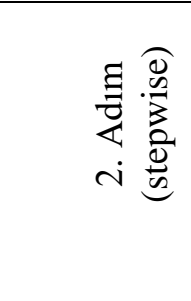 } & (sabit) & 2.66 & .46 & & 5.75 & .000 \\
\hline & $\begin{array}{l}\text { cinsiyet } \\
\text { (dummy) }\end{array}$ & .09 & .09 & .05 & 1.02 & .304 \\
\hline & yas & .01 & .01 & .17 & .99 & .321 \\
\hline & kıdem & -.02 & .01 & -.23 & -1.39 & .165 \\
\hline & yönlendirici dil & -.23 & .05 & -.24 & -4.59 & .000 \\
\hline
\end{tabular}

Bağımlı değişken tükenmişlik

R2değişim $=.058 \quad * \mathrm{p}<.05, * * \mathrm{p}<.01, * * * \mathrm{p}<.001$

Yapılan çoklu regresyon analizinde, demografik değişkenler 1.adımda kontrol edilerek 2. adımda stepwise ile motivasyonel dilin yönlendirici dil, empatik dil ve anlam oluşturucu dil boyutları modele eklendikten sonra, tükenmişlik değişkeninin motivasyonel dilin yönlendirici dil $(\beta=-.24 * * *, p<0.001)$ alt boyutu tarafından anlamlı bir şekilde yordandığı görülmektedir. Motivasyonel dilin empatik dil ve anlam oluşturucu dil alt boyutları, öğretmen tükenmişliğini anlamlı olarak yordamadığından regresyon analizinden (stepwise yöntemiyle) elenmiştir. Her bir birimlik öğretmenin yönlendirici dil kullanımı algısındaki artış .24 birimlik öğretmen 
tükenmişliğini azaltmaktadır. Okul yöneticisinin kullandığı motivasyonel dilin yönlendirici dil alt boyutu, öğretmen tükenmişliğindeki toplam varyansın \%5.8'ini açıklamaktadır $(\Delta \mathrm{R} 2=.058$; $\mathrm{p}<0.001$ ). Okul yöneticisinin motivasyonel dilin alt boyutu olan yönlendirici dil kullanımına ilişkin olumlu algılar arttıkça, öğretmenin tükenmişlik düzeyinin düşük düzeyde de olsa azaldığı söylenebilir.

\section{Tartışma / Sonuç ve Öneriler}

$\mathrm{Bu}$ çalışmanın sonuçlarına göre, okul yöneticilerinin öğretmenler tarafindan algılanan motivasyonel dili, öğretmen tükenmişliğini negatif anlamlı olarak yordamaktadır. Ayrıca motivasyonel dilin boyutlarından sadece yönlendirici dilin, öğretmen tükenmişliğini negatif anlamlı olarak yordadığ tespit edilmiştir. Dolayısıyla araştırmada test edilen hipotezlerden H1 ve $\mathrm{H} 2$ doğrulanmıştır. Motivasyonel dilin empatik dil ve anlam oluşturucu dil alt boyutlarının ise öğretmen tükenmişliğini anlamlı olarak yordamadığı tespit edilmiştir. Dolayısıyla H3 ve H4 hipotezleri doğrulanmamıştır. Ayrıca çalışmada, öğretmen algılarına göre okul yöneticilerinin en fazla yönlendirici dili, en az ise anlam oluşturucu dili kullandıkları açığa çıkarılmıştır.

Önceki çalışmalarda (Chory-Assad, 2002; Demir, 2018a; Lüscher ve Lewis, 2008; Mayfield ve Mayfield, 2006; Mayfield ve diğerleri, 1998; Mert, 2011; Sullivan, 1988) astların algılarına göre, yöneticilerin en fazla kullandığı motivasyonel dil boyutunun yönlendirici dil, en az kullandığının ise anlam oluşturucu dil olduğu görülmektedir. Dolayısıyla, öğretmen görüşlerine dayanan bu çalışmada da öğretmen algılarına göre yöneticilerin en fazla kullandığ motivasyonel dil bileşeni yönlendirici dil ve en az kullanılan bileşenin ise anlam oluşturucu dil olduğu bulgusu desteklenmektedir. $\mathrm{Bu}$ araştırmanın motivasyonel dilin yönlendirici dil boyutunun tükenmişliği azalttığı bulgusuna dayalı olarak, öğretmenlerin tükenmişlik düzeylerini azaltmak isteyen okul yöneticilerinin yönlendirici dil kullanımına yoğunlaşmalarının önemli olduğu belirtilebilir.

Liderin stratejik iletişiminin bir metodu olan motivasyonel dilin; örgütlerde iş doyumu, örgütsel bağlılık, motivasyon, öz yeterlik, memnuniyet gibi istenen çalışan çıktıları ile pozitif anlamlı (Brannon, 2011; Demir, 2018a, 2018b, 2018c; Gutierrez-Wirsching ve diğerleri, 2015; Mayfield ve Mayfield, 2002; Mayfield ve diğerleri, 1995, 1998; Sullivan, 1988) ve işten ayrılma niyeti gibi çalışan çıktıları ile de negatif anlamlı ilişkili (Mayfield ve Mayfield, 2007) olduğu bilinmektedir. Dolayısıyla motivasyonel dil, olumlu çalışan tutumlarını arttırmakta ve olumsuz çalışan çıktılarını ise azaltmaktadır. Motivasyonel dil ile tükenmişlik ilişkisini doğrudan inceleyen bir çalışmaya rastlanılmamış olmasına rağmen ilgili alanyazın bu kavramların birbiriyle negatif ilişkili olduğunu işaret etmektedir. Demir (2018c) araştırmasında; kullanılan bu iletişim metodu ile öğretmenlerin okullarında işlerinden dolayı bir gerilim yaşamalarının önüne geçilebildiğini bulmuştur. Önceki çalışmalarda (Bradley, 2014; Kreitner ve Kinichi, 2009; Schermerhorn ve diğerleri, 2011); stres ve gerilim duygularının uzun süre ve yoğun biçimde yaşanmamasının, tükenmişliği azalttığı görülmüştür. $\mathrm{Bu}$ çalışmada da okul yöneticisinin algılanan motivasyonel dilinin, öğretmen tükenmişlik düzeyini azalttığı tespit edilmiştir.

Altıntaş (2014), çalışanların performanslarının iyi olmasında ve işleriyle ilgili gerilim yaşamamalarında, örgütün kendilerinden neler beklediğini tam olarak bilmelerinin gerektiğini ileri sürmektedir. Aksi takdirde uzun süreli gerilimler ve bu gerilimler karşısında çaresizlik yaşanması, tükenmeye neden olmaktadır. Simmons ve Sharbrough III (2013), çalışanların bir davranışın belirgin bir amaçla gerçekleşeceğini bilmelerinin, buna inanmalarının ve sonuca yükledikleri anlamların değerli hale gelmesinin liderin iletişim becerileriyle gerçekleştiğini ortaya çıkarmışlardır. Schwap ve Iwanichi (1982), rol çatışması ve rol belirsizliğinin bulunduğu okullarda öğretmenlerin öğrencilere yönelik olumsuz tavırlar sergilemesinin yanı sıra, duygusal tükenme ve yorgunluk yaşadıklarını tespit etmiş̦tir. Okul yöneticisinin amaçları belirginleştirici mesajlar vermesinin, kurum olarak öğretmenlerden neler beklediğini açıklamasının, rolleri belirgin hale getirmesinin diğer bir ifadeyle iki ya da daha fazla birbiriyle tutarsız rolleri aynı anda beklememesinin, belirsizlikleri azaltmasının, hak ve sorumluluklar ile bunların nasıl gerçekleştirileceğine ilişkin açık ve net bilgiler vermesinin ve faydalı yönlendirmelerde 
bulunmasının, kullanacakları stratejik iletişim metodu aracılığıyla gerçekleştirecekleri görülmektedir. Bu araştırmada da benzer olarak, okul yöneticisinin yönlendirici dil kullanımına ilişkin olumlu algıların artmasının, öğretmenlerin tükenmişliklerini azalttığı görülmüştür.

Motivasyonel dilin anlamlı ve en küçük parçaları olan yönlendirici dil, empatik dil ve anlam oluşturucu dil söz edimlerinden sadece yönlendirici dilin öğretmen tükenmişliğini negatif anlamlı yordadığı tespit edilmiştir. Bu araştırmanın bulguları, Motivasyonel dil teorisinin dört ana varsayımından biri olan "Liderler, etkili sonuçlara ulaşmak için motivasyonel dilin her üç unsurunu da uygun bir şekilde birlikte kullanırlar." şeklindeki varsayımının, öğretmen tükenmişliği çıktısına yönelik olarak geçerli olmadığını göstermiştir. Elde edilen bulgular, teorinin ana varsayımlarından biri ile ilgili bir takım soru işaretleri ortaya çıkarmaktadır. Motivasyonel dil kullanımının öğretmen tükenmişliği ile olan bağında, motivasyonel dilin alt boyutlarından öğretmen tükenmişliği ile incelenmesinin, bu teorinin anlaşılmasına ve başarılı bir şekilde uygulanmasına daha fazla katkı sağlamaktadır.

Örneklem Hatay il merkezindeki ortaokullarda çalışan öğretmenlerle sınırlıdır. Diğer bir sınırlılığı ise, değişkenler arasında neden-sonuç ilişkilerine dair fikirler verilmiş ancak tespit edilen ilişkilerin nedenleri derinlemesine incelenmemiştir. Araştırmanın sınırlılıklarına rağmen, motivasyonel dil ve tükenmişlik değişkenlerine yönelik birçok önemli bulgu elde edildiği görülmektedir. Gelecek çalışmalar, bu araştırmanın genellenebilirliği açısından farklı çalışma koşullarında ve kültürlerde yinelenebilir. Bu iki kavram arasındaki ilişkiye dair deneysel çalışmalar tasarlanabilir. Böylelikle motivasyonel dilin tükenmişlik üzerindeki farklı potansiyel etkilerinin neler olduğu ve bu iki kavram arasındaki bağların nasıl farklılaşabileceği incelenebilir. Motivasyonel dil kullanımının olumlu çalışan tutumlarıyla ilişkilerini ortaya koyan çalışmalar bulunmasına rağmen olumsuz tutumlarla ilişkisini ortaya koyan çalışmalar oldukça sınırlıdır. $\mathrm{Bu}$ bağlamda motivasyonel dil teorisine ilişkin kavramsal çerçevenin genişletilmesi, bu teorinin daha iyi anlaşılması ve daha kolay uygulanabilmesi için motivasyonel dilin olumsuz tutumlarla da incelendiği çalışmalara ihtiyaç duyulmaktadır.

\section{Kaynaklar}

Altıntaş, E. (2014). Stres yönetimi. Ankara: Anı Yayıncılık.

Arbuckle, J. (2009). Amos 18 user's guide. Armonk, NY: IBM/SPSS Incorporated.

Aliyev, R. ve Tunç, E. (2015). Self-efficacy in counseling: The role of organizational psychological capital, job satisfaction, and burnout. Procedia - Social and Behavioral Sciences, 190, 97-105.

Banks, T. (2014). The effects of leader speech and leader motivating language on employee self-esteem (Unpublished doctorate dissertation). School of Business \& Leadership, Regent University, USA.

Bolat, O. İ. (2011). Öz yeterlik ve tükenmişlik ilişkisi: Lider-üye etkileşiminin aracıllk etkisi. Ege Akademik Bakıs, 11(2), 255-266.

Brannon, K. L. (2011). The effects of leader communication medium and motivating language on perceived leader effectiveness (Unpublished doctorate dissertation). Northcentral University, Graduate Faculty of the School of Psychology, Prescott Valley, Arizona, USA.

Bradley, K. (2014). Educator's positive stress responses: Eustress and psychological capital. (Unpublished doctorate dissertation). DePaul University, Chicago, USA.

Büyüköztürk, Ş., Çakmak, E. K., Akgün, Ö. E., Karadeniz, Ş. V. ve Demirel, F. (2012). Bilimsel araştırma yöntemleri. Ankara: Pegem A.

Byrne, B. M. (2010). Structural equation modeling with AMOS. New York: Routledge.

Byrne, B. M. (1991). Burnout: Investigation the impact of background variables for elementary, intermediate, secondary and university educators. Teachers and Teaching Education, 7(2), 197-209.

Chory-Assad R. M. (2002). Classroom justice: Perceptions of fairness as a predictor of student motivation, learning, and aggression. Communication Quarterly, 50(1), 58-77. 
Conger, J. (1991). Inspiring others: The language of leadership. Academy of Management Executives, 1, 31-44.

Çokluk, Ö. (2014). Örgütlerde tükenmişlik. C. Elma ve K. Demir (Yay. haz.). Yönetimde Çağdaş Yaklaşımlar Uygulamalar ve Sorunlar, içinde (s.117-143). Ankara: Anı Yayıncilik.

Demir, S. (2018a). Okul yöneticilerinin motivasyonel dili ile öğretmen öz yeterliği arasındaki ilişki üzerine bir çalışma. Anemon Muş Alparslan Üniversitesi Sosyal Bilimler Dergisi, 6(2), 177-183. DOI: 10.18506/anemon.384848

Demir, S. (2018b). Okul yöneticilerinin kullandıkları motivasyonel dil ile öğretmen motivasyonu arasındaki ilişsi. Anemon Muş Alparslan Üniversitesi Sosyal Bilimler Dergisi, 6(5), 633-638. DOI: 10.18506/anemon.395472

Demir, S. (2018c). Okul yöneticilerinin kullandıkları motivasyonel dil ile ögrretmen motivasyonunun incelenmesi (Yayımlanmamış doktora tezi). Gaziantep Üniversitesi Eğitim Bilimler Enstitüsü, Gaziantep.

Dolgun, U. (2015). Tükenmişlik sendromu. D. E. Özler (Yay. haz.). Örgütsel Davranışta Güncel Konular, içinde (s. 287-310). Bursa: Ekin Basım Yayın Dağıtım.

Field, A. (2009). Discovering statistics using SPSS. Dubai: Oriental Press.

Fraenkel, J. R., Wallen, N. E. ve Hyun, H. H. (2012). How to design and evaluate research in education. New York: McGraw-Hill.

Gam, J., Kim, G. ve Jeon, Y. (2016). Influences of art therapists' self-efficacy and stress coping strategies on burnout. The Arts in Psychotherapy, 47, 1-8.

Gutierrez-Wirsching, S., Mayfield, J., Mayfield, M. ve Wang, W. (2015). Motivating language as a mediator between servant leadership and employee outcomes. Management Research Review, 38(12), 1234-1250.

Hock, R. R. (1988). Professional burnout among public teachers. Public Personel Management, 17(2), 167-189.

Karaaslan, Ö. (2010). Motivasyonel dilin örgütsel vatandaşlık davranışı ile olan ilişkisinde lider üye etkileşimin aracılı etkisinde incelenmesi: Yapısal eşitlik modelinde bir uygulama (Yayımlanmamış yüksek lisans tezi). Stratejik Araştırmalar Enstitüsü, Harp Akademileri Komutanlı̆ğ İstanbul.

Karasar, N. (2012). Bilimsel araştırma yöntemi. Ankara: Nobel Yayınları.

Kline, R. B. (2011). Principles and practice of structural equation modeling. New York: The Guilford Press.

Kreitner, R. ve Kinichi, A. (2009). Organizational behaviour. New York: Mc Graw-Hill International Edition, Ninth edition.

Kyriacou, C. (2000). Stress-busting for teachers. London: Nelson Thornes Ltd.

Lüscher, L. S. ve Lewis, M. W. (2008). Organizational change and managerial sensemaking: Working through paradox. Academy of Management Journal, 51(2), 221-240.

Mayfield, J. ve Mayfield, M. (2002). Leader communication strategies: Critical paths to improving employee commitment. American Business Review, 20(2), 89-94.

Mayfield, J. ve Mayfield, M. (2004). The effects of leader communication on worker innovation. American Business Review, 22(2), 45-51.

Mayfield, J. ve Mayfield, M. (2006). The benefits of leader communication on part-time worker outcomes: A comparison between part-time and full-time employees using motivating language. Journal of Business Strategies, 23(2), 131-153.

Mayfield, J. ve Mayfield, M. (2007). The effects of leader communication on a worker's intent to stay: An investigation using structural equation modeling. Human Performance, 20(2), 85-102, DOI: 10.1080/08959280701332018.

Mayfield, M. ve Mayfield, J. (2009a). The role of leader-follower relationships in leader communication: A test using the LMX and motivating language models. The Journal of Business Inquiry, 8(1), 65-82.

Mayfield, J. ve Mayfield, M. (2009b). The role of leader motivating language in employee absenteeism. Journal of Business Communication, 46(4), 455-479. 
Mayfield, J. ve Mayfield, M. (2010). Leader-level influence on motivating language. Competitiveness Review, 20(5), 407-422. DOİ: 10.1108/10595421011080788.

Mayfield, J., Mayfield, M. ve Kopf, J. (1995). Motivational language: Exploring theory with scale development. The Journal of Business Communication, 32(4), 329-344.

Mayfield, J., Mayfield, M. ve Kopf, J. (1998). The effects of leader motivating language on subordinate performance and satisfaction. Human Resource Management, 37(3-4), 235248.

Mert, İ. S. (2011). Yöneticilerin kullandıkları motivasyonel dil ve performans üzerindeki etkisi. Balıkesir Üniversitesi Sosyal Bilimler Enstitüsü Dergisi, 14(26), 197-214.

Murray, K. (2015). Liderk dili. Ü. Şensoy (Çev.). İstanbul: Türkiye İş Bankası Kültür yayınları.

Pines, A. M. (2005). The burnout measure short version (BMS). International Journal of Stress Management, 12(1), 78-88.

Özdamar, K. (2003). Modern bilimsel araştırma yöntemleri. Eskişehir: Kaan Kitabevi.

Özen, H. (2013). Okul müdürlerine yönelik motivasyonel dil ölçeği: Türk kültürüne uyarlama, dil geçerliği ve faktör yapısının incelenmesi. Eğitim Bilimleri Araştırmaları Dergisi, 3(1), $87-103$.

Rahmati, Z. (2015). The study of academic burnout in students with high and low level of selfefficacy. Procedia - Social and Behavioral Sciences, 171, 49-55.

Rogala, A., Shoji, K., Luszczynska, A., Kuna, A., Yeager, C., Benight, C. C. ve Cieslak, R. (2016). From exhaustion to disengagement via self-efficacy change: Findings from two longitudinal studies among human services workers. Frontiers in Psychology, 6(2032), 112. DOİ: $10.3389 /$ fpsyg.2015.02032.

Russell, D. W., Altmaier, E. ve Van Velzen, D. (1987). Job-related stress, social support, and burnout among classroom teachers. Journal of Applied Psychology, 72(2), 269-274.

Sarıçam, H. ve Sakız, H. (2014) Burnout and teacher self-efficacy among teachers working in special education institutions in Turkey. Educational Studies, 40(4), 423-437.

Schwab, R. H. ve Iwanicki, E. F. (1982). Who are our burned out teachers? Educational Research Quarterly, 7(2), 5-17.

Schermerhorn, J. R., Hunt, J. G., Osborn, R. N. ve Uhl-Bien, M. (2011). Organizational behavior. Asia: John Wiley \& Sons (Asia) Pte Ltd.

Simmons, S. A. ve Sharbrough III, W. C. (2013). An analysis of leader and subordinate perception of motivating language. Journal of Leadership, Accountability and Ethics, 10(3), 11-27.

Sönmez, V. ve Alacapınar, F.G. (2016). Örneklendirilmiş bilimsel araştırma yöntemleri. Ankara: Anı yayıncilık.

Sullivan, J. J. (1988). Three roles of language in motivating theory. The Academy of Management Review, 13(1), 104-115.

Tümkaya, S., Çam, S. ve Çavuşoğlu, I. (2009). Tükenmişlik ölçeği kısa versiyonu'nun Türkçe'ye uyarlama, geçerlik ve güvenirlik çalışması. C. U. Sosyal Bilimler Enstitüsü Dergisi, 18(1), 387-398.

\section{Extended Abstract}

\section{Introduction}

Strategical verbal communication is considered as one of the most important leadership competences that must be possessed by leaders. This kind of leader communication provides positive individual and organizational outcomes. Despite this fact, there is limited studies to focus on motivational language in the organizations. So, determining the relationship between motivational language and burnout is considered to make an important support to the field due to presenting a new conceptual model. This study also gives a deep insight of school administrator's motivational language and teacher's burnout. 
This study has aimed to reveal the relationships between the motivating language and its facets with the teacher's burnout. In accordance with this aim, this study focuses on testing these hypothesises:

H1: School administrator's motivational language predicts positively and significantly teachers' burnout.

H2: School administrator's directing-giving language predicts positively and significantly teachers' burnout.

H3: School administrator's empathetic language predicts positively and significantly teachers' burnout.

H4: School administrator's meaning-making language predicts positively and significantly teachers' burnout.

\section{Method}

Relational screeing model was used in this research. Motivational language, its sub-facets (directing-giving, empathetic and meaning-making language) and burnout were examined through surveys and the correlations among these variables were determined. Then whether motivational language and sub-facets are a significant predictor for burnout were investigated.

Collected data was first entered to SPSS. Demographic characteristics of participants, descriptive statistics, correlation analysis and regression analysises were conducted via this program. Motivational language, its sub-facets (directing-giving, empathetic and meaningmaking language) and burnout were examined through surveys and the correlations among these variables were determined. Then whether motivational language and sub-facets are a significant predictor for burnout were investigated.

The research sample consists of 348 teachers in 33 middle schools that were selected randomly at Hatay's city center in 2017-2018 academic year. As mentioned Field (2009) and Özdamar (2003), this sample size is enough at 95\% confidence interval for this population of study. While $53.4 \%$ of the teachers participating in this study are male $(\mathrm{n}=186), 46.6 \%$ are female $(n=162) .71 .3 \%$ of the participants are married $(n=248)$, whereas $28.7 \%$ of them are single $(n=100)$. While the most frequent age range of the participants is $31-40$ years $(n=123)$ with a percentage of $39.1 \%$, the least frequent age range is 41 years and up $(n=79)$ with a percentage of $4.5 \%$. The most frequent senior range of the participants is $1-10$ years $(n=189)$ with a percentage of $54.3 \%$, the least senior age range is 21 years and up $(n=37)$ with a percentage of $10.6 \%$.

Data of this study were collected through five-point Likert-type scales. The points of the scale are differentiated as $1=\mathrm{I}$ don't agree at all; $2=\mathrm{I}$ don't agree; 3= I agree partially; 4= I agree; and 5= I totally agree. Two different scales were used in this study as follows. Motivational language scale that was developed by Mayfield et al. (1995) and adapted to Turkish by Özen (2013). The Kaiser-Meyer-Olkin (KMO) value was calculated to be .952 and the results of Bartlett test of sphericity were meaningful $(\mathrm{p}<.001)$. The orginal threedimensioned factorial structure has been confirmed. Directing-giving facet explained $34.211 \%$ of the total variance on its own, while empathetic language facet explained $14.373 \%$, and meaning-making language facet explained $28.606 \%$. These three dimensions explained 77.189 $\%$ of the total variance on the scale. Cronbach's Alpha of the overall scale was calculated as 0.962. Cronbach's Alpha coefficients of three dimensions were as follows; Directing-giving language: .950, Empathetic language: .865, Meaning-making language: .939.

Burnout scale was developed by Pines (2005) and adapted to Turkish by Tümkaya, Çam and Çavuşoğlu (2009). The Kaiser-Meyer-Olkin (KMO) value was found as .926 and the results of Bartlett test of sphericity were meaningful ( $\mathrm{p}<.001$ ). A single factor consisted of ten items explaining \%64.045 of the total variance. Cronbach's Alpha of this scale was determined to be 0.934 . 


\section{Result and Discussion}

Regression analysis results have indicated that motivational language used by school administrators reduces teacher burnout. Whereas empathetic and meaning-making sub-facets of motivational language haven't predicted teacher burnout significantly, directing-giving subfacet has predicted significantly which means only directing-giving sub-facet of motivational language provides a decrease in teachers' level of burnout. So, as mentioned above H1 and H3 has been confirmed, but $\mathrm{H} 3$ and $\mathrm{H} 4$ has not been confirmed. The researcher has pointed out one of the basic assumptions that leaders have to use all three sub-facets of motivational language together properly to get positive employee outputs has not been confirmed in terms of decreasing burnout.

This research would contribute to the importance of using strategical applications of verbal communication by school administrators. The researcher asserts that motivational languge can reduce teachers' negative attitudes at schools. Motivational language is an efficient method of strategical verbal communication so as to support efficacy and productivity in organizations. 